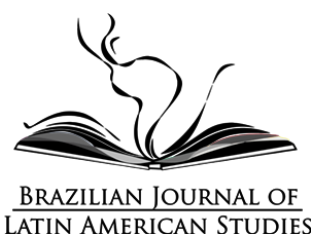

\title{
EL ASCENSO DE CHINA Y LAS DISPUTAS ESTRATÉGICAS EN LOS GRUPOS DOMINANTES DE LOS ESTADOS UNIDOS'
}

\author{
A ASCENSÃO DA CHINA E AS DISPUTAS ESTRATÉGICAS NOS GRUPOS \\ DOMINANTES DOS ESTADOS UNIDOS \\ THE RISE OF CHINA AND THE STRATEGIC DISPUTES IN THE DOMINANT \\ GROUPS OF THE UNITED STATES
}

Gabriel E. Merino ${ }^{2}$ iD

Universidad Nacional de La Plata, Argentina

\begin{abstract}
Resumen: El sistema mundial se encuentra en plena transición histórico-espacial. La crisis de hegemonía se refleja en un conjunto de conflictos en donde los poderes dominantes no logran imponerse, como también en el cambio en las jerarquías del sistema interestatal y en las profundas transformaciones de la economía mundial. Frente a esta situación, surgen distintas respuestas imperiales y se profundiza la polarización entre proyectos políticos estratégicos en Estados Unidos, al calor de una fractura en su "establishment". En este sentido, en el presente ensayo se examinan aspectos centrales de la geopolítica y de las estrategias en disputa en los Estados Unidos frente al ascenso de China y al declive de su poder relativo. Desde esta perspectiva, se analizan las reconfiguraciones imperiales en marcha a partir del triunfo de Donald Trump, cuando se produce un giro nacionalista-americanista contrario a las fuerzas globalistas. Además, se observan elementos clave del ascenso de China, sus aspectos geopolíticos y sus respuestas frente a las geoestrategias dominantes de Washington. Una de las conclusiones a las que se arriba en la investigación es que el giro nacionalista-americanista puede favorecer el ascenso de China, a la vez que profundiza la crisis del orden mundial.
\end{abstract}

Palabras clave: Transición Histórica-Espacial, China, Estados Unidos, Hegemonía, Nuestra América

\footnotetext{
'Este trabajo tiene como base la ponencia presentada como ponencia en la $\vee$ Conferencia de Estudios Estratégicos, La Habana, octubre de 2019. La misma continúa un conjunto de investigaciones publicadas en Merino (2014, 2016, 2018a, 2018b, 2019) y Merino (2019).

2 Doctor en Ciencias Sociales, investigador del CONICET (Argentina), docente e investigador de la Universidad Nacional de La Plata (UNLP), Instituto de Investigación en Humanidades y Ciencias Sociales (IdIHCS) e Instituto de Relaciones Internacionales (IRI), Co-coordinador del Grupo de Trabajo de CLACSO "China y el mapa del poder mundial".
}

Brazilian Journal of Latin American Studies - Cadernos Prolam/USP, v. 19, n. 37, p. 44-77, out. 2020. Edição 
Resumo: O sistema mundial está em plena transição histórico-espacial. A crise da hegemonia se reflete em um conjunto de conflitos em que os poderes dominantes deixam de se impor, bem como na mudança nas hierarquias do sistema interestatal e nas profundas transformações da economia mundial. Diante dessa situação, surgem diferentes respostas imperiais e se aprofunda a polarização entre projetos políticos estratégicos nos Estados Unidos, no calor de uma fratura em seu "establishment". Nesse sentido, este ensaio examina aspectos centrais da geopolítica e as estratégias em disputa nos Estados Unidos diante da ascensão da China e do declínio de seu poder relativo. Nesta perspectiva, são analisadas as reconfigurações imperiais em andamento desde a vitória de Donald Trump, quando há uma virada nacionalista-americana ao contrário das forças globalistas. Além disso, são observados os principais elementos da ascensão da China, seus aspectos geopolíticos e suas respostas às geoestratégias dominantes de Washington. Uma das conclusões alcançadas na investigação é que a virada nacionalista-americanista pode favorecer a ascensão da China, aprofundando a crise da ordem mundial.

Palavras-chave: Transição Histórico-Espacial, China, Estados Unidos, Hegemonia, Nossa América

Abstract: The world system is in historical-spatial transition. The crisis of hegemony is reflected in a set of conflicts in which the dominant powers fail to impose themselves, as well as in the change in the hierarchies of the interstate system and in the profound transformations of the world economy. Faced with this situation, different imperial responses arise and the polarization between strategic political projects in the United States deepens, in relation to a fracture in its "establishment". In this sense, this article examines central aspects of geopolitics and the disputed strategies in the United States against the rise of China and the decline of its relative power. From this perspective, we analyze the imperial reconfigurations underway since the triumph of Donald Trump, when there is a nationalist-Americanist turn, contrary to globalist forces. In addition, key elements of China's rise, its geopolitical aspects and its responses to the dominant geostrategies of Washington are observed. One of the conclusions reached in the investigation is that the nationalist-Americanist turn can favor the rise of China, while deepening the crisis of the world order.

Keywords: Historical-Spatial Transition, China, United States, Hegemony, Nuestra América 


\section{Introducción}

La transición histórica-espacial actual del sistema mundial se manifiesta, entre otros modos, como una crisis económica y una crisis de la hegemonía estadounidense y del orden mundial construido por el polo de poder angloamericano. Son dos caras de la misma moneda y parte de la crisis civilizatoria. La acumulación está siempre en relación al poder político y militar que la garantiza (que sanciona las reglas de juego, construye monopolios para la valorización del valor, conquista territorios, disciplina a los rivales, otorga legitimidad, etc.). Y el poder político y militar se nutre del poder económico y de la acumulación sin fin de valor para procurarse los recursos de su propia reproducción ampliada. Esta es la naturaleza del imperialismo moderno.

La transición histórica en su dimensión geopolítica comienza a percibirse claramente a partir de 1999-2001, cuando brota germinalmente la situación de multipolaridad relativa que hoy vivimos, como reacción a la globalización financiera neoliberal estadounidense-angloamericana y su expansión política y militar. El declive relativo de Estados Unidos y "Occidente", por un lado, y la reemergencia de China y Asia-Pacífico, por el otro, es una de las características centrales del cambio de época que vivimos, el cual no puede ser interpretado solamente como una transición hegemónica más dentro del moderno sistema mundial. Es decir, como parte de la sucesión de ciclos de hegemonía del sistema mundial moderno iniciados en el siglo XV como los analiza Arrighi (2007) y Arrighi y Silver (2001), mediados por períodos de transición que caracterizados por "guerras de 30 años" (entre 25 y 40 años): ibérico-genovés, holandés, británico, estadounidense ${ }^{3}$. Lo que sí es común en la actual transición, como en las anteriores, es que en los territorios periféricos y semiperiféricos se producen movimientos nacionales populares y emergencias revolucionarias que, entre otras cuestiones, buscan aumentar los niveles de soberanía o de autodeterminación relativa real, modificar su inserción subordinada en la jerarquía interestatal y en la división internacional del

\footnotetext{
${ }^{3}$ El sistema-mundo moderno surgido en occidente no comprende a China y a la India como parte totalmente integrada al mismo hasta el ciclo de hegemonía británico y la periferialización de dichas regiones como colonias y semicolonias. En este sentido, tomamos la teoría del Sistema Mundo y los ciclos de hegemonía que desarrolla como parte del marco teórico aquí utilizado, aunque de forma crítica y articulada a otras herramientas teórico-metodológicas.
} 
trabajo, limitar la extraversión de valor de sus territorios, mejorar las condiciones de las clases populares, etc.

La reemergencia de China, el ascenso de Asia-Pacífico, las alianzas con Rusia, el creciente desarrollo de un espacio Euroasiático y la insubordinación antihegemónica impulsada por fuerzas del Sur Global constituyen expresiones de la crisis de los elementos constitutivos del moderno sistema mundial: su carácter eurocéntrico u "occidentalocéntrico", su carácter capitalista "clásico", su particular ordenamiento centro-semiperiferia-periferia y la especificidad del imperialismo moderno asociado a la acumulación sin fin del capital y a la resolución de los obstáculos de la acumulación.

Actualmente estamos en el proceso inverso del que sucedió a fines del siglo XVIII y principios del siglo XIX, en donde el imperialismo capitalista occidental encabezado por el Reino Unido logró subordinar y hacer declinar las economías más importantes del mundo, China y la India, convirtiéndolas en periferia. Ello lo logró fundamentalmente por su poderío militar. Este proceso, denominado por algunos como la "Gran Divergencia" (Pomeranz, 2000; Huntington, 1996), lleva a preguntarnos si actualmente estamos frente a una nueva gran divergencia, pero a la inversa.

Una cuestión fundamental de la transición es que los grupos de poder, las clases dominantes, las fuerzas dirigentes de Estados Unidos no acuerdan en qué hacer o cómo enfrentar el ascenso de China, dando lugar a distintas estrategias imperiales -lo cual tiene algunas similitudes con lo acontecido en el Reino Unido desde principios del siglo XX, especialmente en la dimensión económica con la disputa entre proteccionistas (los industriales) y librecambistas (la city financiera). En este sentido, Arrighi (2007) señala distintas opciones estratégicas que surgen en Estados Unidos frente al ascenso del gigante asiático. En primer lugar, se destaca la posición neoconservadora dominante durante el gobierno de Bush, que se centra en la supremacía militar de Estados Unidos, el intervencionismo unilateral y el control de la región de Medio Oriente y de sus recursos hidrocarburíferos como una de las llaves para la primacía mundial. Frente a ello y especialmente debido al fracaso en Irak, emergen desde la perspectiva neorrealista tres estrategias:

1) la de contención de China mediante una coalición de equilibrio y el establecimiento de una alianza militar en el Asia-Pacífico similar a la OTAN y conocida como PACOM, formulada por Robert D. Kaplan, que también se 
extiende al Índico, desde el comando USINDOPACOM (United States Indo-Pacific Command);

2) la estrategia de cooptación y establecimiento conjunto de un sistema internacional estable, una estrategia de contención centrado en las dimensiones políticas y económicas, que comprometa a China a sostener el orden mundial vigente a cambio de concesiones, formulada esencialmente por Henry Kissinger y también efectuada con matices por Zbigniew Brzezinski;

3) la estrategia de "tercero feliz" de los Estados Unidos jugando con la rivalidad de China con otras potencias asiáticas (especialmente India y Japón) y una política neohamiltoniana de industrialización (fuertemente proteccionista) con foco en las industrias vitales para la defensa, formulada por Pinkerton. ${ }^{4}$ Esta última podemos diferenciarla y comprenderla como dos formulaciones articuladas.

También podemos mencionar el internacionalismo liberal, que se centra en la crítica a China por la falta de respeto a los derechos humanos $y$, en general, por el rechazo de la dirigencia China a aceptar la comunidad de valores propuesta por Occidente. El liberalismo argumenta que la guerra no es inevitable y que China puede ser controlada a partir del establecimiento de instituciones y normativas regulatorias para los Estados, no sólo externas sino también internas.

Tomando estos debates, aquí proponemos otra perspectiva para observar las diferencias estratégicas en los Estados Unidos para enfrentar la amenaza que significa para su posición dominante a nivel mundial el ascenso de China y de los polos de poder que configuran un mundo multipolar que erosionó la unipolaridad angloamericana. ${ }^{5}$ Esta otra perspectiva está formulada en base a identificar las fuerzas en pugna en los Estados Unidos, focalizándonos en las disputas entre los que denominamos globalistas, americanistas y nacionalistas. A partir de allí, articulamos discursos, grupos de poder e intereses para identificar dos grandes estrategias imperiales, con sus geoestrategias particulares, y

\footnotetext{
${ }^{4}$ Con distintos matices y valoraciones, en las tres estrategias aparece la idea del equilibrio de poder propio del neorrealismo y que también formula Brzezinski con el objetivo de que Estados Unidos mantenga la primacía: "emplear su influencia en Eurasia para crear un equilibrio continental estable en el que Estados Unidos ejerza las funciones de árbitro político." (Brzezinski, 1998: 11)

${ }^{5}$ Esta perspectiva significa, entre otras cuestiones, analizar los enfrentamientos en los grupos dominantes incorporando elementos de la economía política para observar la "lucha" entre capitales (por ejemplo, entre sus fracciones más dinámicas y las menos), analizar su expresión en el terreno político y los efectos que produce. También se parte de entender al Estado, ante todo, como una relación de fuerzas dinámica, que se cristaliza a su vez en un entramado institucional que posee el monopolio de la violencia legítima en un territorio (lo cual incluye la dimensión simbólica y material). Esto no sólo significa que el Estado no es el único actor en el análisis geopolítico, sino que este está atravesado por luchas entre fuerzas políticas y sociales y sus definiciones geopolíticas y geoestratégicas se modifican en función de estas, en una situación mundial y regional determinada. Algunos de estos elementos se desarrollan en Merino (2015) y Merino (2018a)
} 
comprender las diferentes maneras de enfrentar a China. Partiendo de dicho análisis, en este trabajo se busca comprender las reconfiguraciones imperiales en marcha a partir de la presidencia de Donald Trump. Además, se observan ciertos elementos claves del ascenso de China, sus aspectos geopolíticos y las respuestas del gigante oriental frente a las estrategias en su contra de Washington. Por último, se realiza un análisis de guerra comercial en el marco de las fracturas internas de los Estados Unidos y las pujas geoestratégicas globales.

\section{La fugaz belle époque unipolar globalista}

Las transformaciones en el campo económico, producto del desarrollo del capital financiero transnacional y el cambio en las relaciones capitalistas de producción en la era de la globalización, junto con la ofensiva en los campos político, ideológico y militar del proyecto neoliberal encabezado por los Estados Unidos y el Reino Unido, posibilitó una reconstrucción de la hegemonía estadounidense (Tavares; Fiori, 2017) y, en términos más exactos, angloamericana. Sin lugar a dudas, la caída de la URSS fue fundamental en este sentido. El nuevo ciclo de crecimiento iniciado en 1993-1994 que dejó atrás el ciclo negativo desde los años setenta, consolidó la belle époque neoliberal.

El mundo devino unipolar y emergió el globalismo como descripción ideológica de la nueva fase del capitalismo mundial, pero, también, como proyecto político estratégico. A la transnacionalización financiera, productiva $y$, en buena medida, cultural, debía corresponderle una estructura de poder transnacional que administrara el nuevo orden del sistema mundial y que suturase las contradicciones del capitalismo global. El proyecto de Estados Unidos como estado verdaderamente global era imposible, pero a su vez, sobre su base y desarrollo, se configuró el andamiaje de una institucionalidad globalista, que significó un proceso de debilitamiento de las soberanías nacionales -una desnacionalización progresiva de los estados, a medida que estos se multiplicaban.

Sin embargo, hacia fines de siglo, en el auge de la belle époque neoliberal, comenzaron a manifestarse los primeros síntomas de la crisis. Mientras el levantamiento del campesinado zapatista en el sur de México en 1994 puso en evidencia el feroz impacto en los pobres del Sur Global, hacia 1999 se manifestó un conjunto de contradicciones entre los grupos dominantes del sistema -tanto centrales, como semiperiféricos y periféricos - y comenzaron a observarse en términos políticos y estratégicos los primeros indicios de la particular multipolaridad y de la 
nueva forma geopolítica de la transición. A partir de allí, la reconstrucción de la hegemonía estadounidense de los años ochenta y su esplendor en los noventa empezó a mostrar sus propios límites y contradicciones: si la llamada globalización, la transnacionalización económica y los vínculos con China fueron pilares de dicha reconstrucción, estos elementos contenían a su vez el germen de la crisis de la hegemonía estadounidense.

En este sentido, si hacia el fin del milenio los BRICS ${ }^{6}$ aparecían como los espacios fundamentales de la expansión del capital transnacional del Norte Global, nueva solución espacial a la acumulación del capital, e integrados progresivamente como semiperiferias en las instituciones internacionales de gobernabilidad global creadas por Occidente, también se observará lo que pocos años después será una realidad poco feliz para el establishment defensor del orden mundial entonces vigente: el desarrollo en algunos países Ilamados "emergentes" o del Sur Global de capacidades estructurales y fuerzas político-sociales desafiantes de las jerarquías estatales establecidas y del lugar asignado en la división internacional del trabajo.

El ataque militar unilateral de la OTAN conducida por Estados Unidos a Yugoslavia en 1999, y el bombardeo a Belgrado, en donde las fuerzas estadounidenses destruyen la embajada china, comienza a mostrar los límites de la creencia del "fin de la historia". A su vez, en dicho año China recupera Macao, mientras que dos años antes, había recuperado la soberanía de Hong Kong, colonia del imperio británico desde 1842 y probablemente el primer hito geopolítico de la Gran Divergencia, iniciada con las guerras del opio, en un camino de subordinación y periferialización de China. Esto, junto a la consolidación de la Organización para la Cooperación de Shanghái con Rusia y los países de Asia central en 2001, son algunas de las manifestaciones geopolíticas de un cambio de época.

Otro indicio del cambio de época sería la captura por parte de Beijing de un avión espía estadounidense que colisionó con un avión caza chino en abril de 2001 en el Mar de China, obteniendo acceso a material electrónico de vigilancia de alta tecnología, extremadamente secreto, en un aparato considerado una fortaleza tecnológica aérea. También mostró la creciente hostilidad de Beijing a los desafíos a su soberanía territorial. Esto se produjo en medio de un profundo cambio en el encuadramiento de la relación bilateral por parte de Estados Unidos frente al gigante asiático con la asunción del gobierno de George W. Bush, que pasó de "asociación estratégica en el siglo XXI" al de "competencia estratégica". Las

\footnotetext{
${ }^{6}$ Acrónimo acuñado por Jim O’Neal de Goldman Sachs y para quién la capital de estos mercados emergentes
} era Londres. 
implicancias de este nuevo encuadramiento incluían la posibilidad de que Estados Unidos venda armas modernas a Taiwán y construya un escudo antimisiles alrededor de China.

Por otro lado, a partir del encuadramiento "competencia estratégica" se pasó a considerar a China como una amenaza en el "patio trasero" estadounidense, por su creciente influencia en América Latina. Ya en el año 2005, durante un debate sobre "La influencia de China en América latina" organizado por el Subcomité para el Hemisferio Occidental del Congreso de Estados Unidos, legisladores y funcionarios del Departamento de Estado y del Pentágono coincidían en que la influencia de China crecía cada día más en Argentina, Brasil, Venezuela y el resto de América latina y que ello representaba "una 'preocupación' para el desarrollo de la democracia y los derechos humanos en el continente." (Alconada Mon, 2005).

La creciente tensión con China desde 1999 y el cambio en los Estados Unidos, que como veremos es producto de una modificación de relación de poder a favor de lo que llamamos el "americanismo" en dicho país, también coincide con un conjunto de hechos que marcan el comienzo del fin de la belle époque neoliberal unipolar: a) el establecimiento del euro por parte de las fuerzas 'continentalistas' de Europa, conducidas por Berlín y París, en su búsqueda por fortalecerse y ganar mayores márgenes de maniobra frente a su aliado y "protector" fundamental, los Estados Unidos. b) La asunción de Putin en Rusia, que expresará la reemergencia de las fuerzas nacionales de la potencia euroasiática. c) La asunción de Hugo Chávez en Venezuela, que indicará una primera fisura de la hegemonía estadounidense y del Consenso de Washington en América Latina, junto con la crisis en Brasil que debilitó a las fuerzas neoliberales en el "gigante" suramericano y las fracturas de los grupos de poder y clases dominantes en Argentina con la aparición del Grupo Productivo, a lo que se le agregó la creciente resistencia de las clases populares (Merino, 2015). También debemos sumar en este punto la crisis de Ecuador, cuya salida fue la dolarización y un ciclo de inestabilidad política que terminaría en el ascenso de Rafael Correa al poder en 2005, y hacia el año 2000, la guerra del agua en Bolivia, punto clave del proceso nacional popular que lleva al Movimiento al Socialismo al Gobierno años después (García Linera, 2008). d) El lanzamiento del Jubileo de la Deuda 2000 por parte de la iglesia católica que propuso condonar la deuda a los países pobres, acompañado de una crítica al neoliberalismo y al capitalismo "salvaje". Es decir, allí comienzan a observarse las primeras manifestaciones geopolíticas de la crisis de hegemonía estadounidense y del orden mundial vigente, la cual 
se mostrará con mayor claridad a partir del fracaso de la guerra en Irak y la crisis global de 2008.

\section{Fractura en Estados Unidos e imperialismo}

El cambio en el encuadramiento por parte del gobierno G. W. Bush de la relación con China a la categoría de "competencia estratégica" debe ser interpretado como parte de los antagonismos que existen en el "establishment" estadounidense (y angloamericano). Las características de la actual fisura en los grupos de poder y clases dominantes comienzan a observarse al final del mandato de Clinton, cuando éste impulsa entre otras cuestiones: a) la derogación de la Ley Glass-Steagall que permite terminar con la división de la banca comercial con la banca de inversión, creando inmensas redes financieras globales; b) la creación del G-20 impulsado por las fuerzas globalistas como nuevo ámbito de gobernabilidad mundial de un capitalismo transnacionalizado; c) el fortalecimiento y/o creación por parte de las fuerzas globalistas de las instituciones internacionales multilaterales (FMI, BM, OMC) en detrimento de las soberanías nacionales, incluso hasta la del propio Estados Unidos según los "americanistas".

Con el gobierno de Bush y, a partir del derribo de las Torres Gemelas, el ascenso del neoconservadurismo en el dominio de la política exterior, se evidencia una reacción "americanista", que se expresa en la puesta en práctica del unilateralismo: se deja de lado la idea del G-20 para retomar el viejo G-7 del Norte Global (Estados Unidos, Canadá, Europa occidental y Japón) y alternativamente el G-8 que incluye a Rusia. Además, se instala un unilateralismo estadounidense-angloamericano, en detrimento del multilateralismo globalista de Clinton, apelando a la supremacía militar y al dominio de región de Medio Oriente para asegurar la posición hegemónica de Estados Unidos en el orden mundial. Lo cual tensiona las relaciones con sus propios aliados, como Francia y Alemania en la guerra de Irak (Harvey, 2004). También se desestima el fortalecimiento excesivo de instituciones internacionales multilaterales, para recuperar poder de decisión directa de los Estados Unidos en detrimento de la "burocracia global"7. A su vez, aplicando un keynesianismo militar (déficit público y aumento superlativo del presupuesto militar, legitimado por la guerra), se buscó dinamizar la

\footnotetext{
${ }^{7}$ En este sentido la editorial del periódico Wall Street Journal, un medio que expresa la voz de las fuerzas "americanistas", afirmó con respecto al accionar del gobierno argentino frente a la embestida de los llamados fondos buitres por la reestructuración de la deuda: "Un default sería tan absurdo que hace pensar en la posibilidad de que Kicillof esté usándolo como una forma de empujar al Fondo Monetario Internacional y a los liberales de América para que intensifiquen su campaña de dejar las negociaciones de deuda en manos de una nueva burocracia mundial. Esto le daría más poder de negociación a los deudores y a los políticos y se lo quitaría a los mercados financieros y a los tribunales de Estados Unidos." 28 de julio de 2014.
} 
economía interna desde el complejo industrial militar. ${ }^{8}$ Por otra parte, como vimos, se definió a China como un competidor estratégico y se puso en práctica una política que Donald Trump iba a llevar mucho más lejos: impedir a las empresas chinas la adquisición de activos considerados estratégicos por parte de Washington. El caso resonante fue el bloqueo a CNOOC de la compra de la petrolera UNOCAL.

La crisis del 2007-2008 con epicentro en Estados Unidos y el Reino Unido fue otro momento fundamental de esta puja al interior de las clases dominantes, entre fracciones financieras, entre globalistas y americanistas (Merino, 2014), en una crisis que puso de manifiesto los límites de la financiarización y el problema de la sobreacumulación. Con el triunfo de Obama, el "globalismo" volvió al gobierno reinstalando en la agenda el multilateralismo-unipolar, el impulso de tratados multilaterales de comercio e inversión, las alianzas militares expansivas en la periferia euroasiática para contener-impedir la emergencia de rivales geopolíticos, el intento de fortalecer las instituciones multilaterales creadas por el Norte Global y el impulso del multiculturalismo como ideología dominante. También los intentos por abandonar las guerras convencionales y centrarse en lo que se denominan guerras híbridas, revoluciones de color y guerras no convencionales. Un ejemplo de esto fue la multiplicación por diez de los ataques con drones en territorios donde Estados Unidos no se encontraba formalmente en guerra, como en Yemen, Somalia o Pakistán, como también el apoyo a fuerzas insurgentes y revoluciones de color en los países con gobiernos contrarios a sus intereses. Su gobierno articuló el programa dominante del capital financiero transnacional (especialmente de origen angloamericano) y los intereses geopolíticos del establishment político e ideológico globalista (que procura incluir a los de sus aliados de Europa Occidental y Japón), con ciertas concesiones a las clases populares estadounidenses a través de programas focalizados y la recuperación parcial de la agenda liberal en relación a los derechos civiles y las libertades individuales. Pero dicha articulación resultaba demasiado contradictoria.

Para las fuerzas globalistas lo que está en juego en el escenario estratégico actual es quien/es escribe/n las reglas de juego del siglo XXI, es decir, la institucionalidad que emerja de esta transición histórico-espacial que atravesamos y que configure un nuevo orden en el sistema mundial, con capacidad para contener a los polos de poder desafiantes. Dicha disputa resulta crucial ya que la geoestrategia de las fuerzas globalistas

${ }^{8}$ De acuerdo a datos del Banco Mundial, luego de una década de caída del gasto militar en relación al gasto total del gobierno central en los Estados Unidos, de 2001 al 2004 subió del 15,15\% a 18,61\%, para mantenerse hasta el 2008 en torno a dicho porcentaje, cuando empieza a caer nuevamente. Y del déficit fiscal del 0,58\% en relación al PIB en 2001 se llegó a un 6,68\% en 2008. 
angloamericanas es inseparable de la lógica del capital transnacional, de las redes financieras globales. Para estas, la actual crisis capitalista sólo se puede "resolver" en sus implicancias geopolíticas (o fugar hacia adelante) en la medida en que se construya el poder político y militar que garantice la acumulación del capital transnacional del Norte Global. Y ello establece una tendencia para avanzar hacia una nueva institucionalidad globalista, hacia el impulso de un imposible Estado global desde Estados Unidos y subordinar-contener a los polos emergentes. Para lo que resulta crucial los acuerdos de libre comercio y las alianzas militares en las periferias Euroasiáticas, regiones claves del rimland.

Como observa Brzezinski, un neorrealista con gran influencia en lo que denominamos globalistas, la "primacía global de los EE.UU. depende directamente de por cuánto tiempo y cuán efectivamente pueda mantener su preponderancia en el continente euroasiático" (Brzezinski, 1998: 39). En este sentido, la tarea es asegurarse que ningún Estado o ningún grupo de Estados obtengan la capacidad de expulsar a Estados Unidos de Eurasia o limitar su papel de árbitro. Y para ello, son fundamentales los acuerdos de libre comercio en la periferia occidental y oriental de Eurasia. Hacia 2014, dichos acuerdos se vuelven todavía más cruciales ante la debilidad la profundización de la crisis de hegemonía estadounidense, la crisis capitalista con epicentro en Occidente, el desafío de las potencias emergentes, el despertar de Oriente, el gran desarrollo de China y la lucha por el control del Pacífico en tanto principal área de acumulación a nivel mundial.

Como expresión de esta geoestrategia que pretendía conducir e incluir al conjunto de las fuerzas de lo que se denomina geopolíticamente como "Occidente" y geoeconómicamente como "Norte Global", Hillary Clinton (2011) afirmaba que el futuro de la política mundial se decidiría en Asia y en el Pacífico, no en Afganistán o Irak -como definen los neoconservadores-, y Estados Unidos debería estar justo en el centro de la acción. Clinton, quien fue Secretaria de Estado de Barack Obama, agregó a esta idea que el eje estratégico de la política exterior norteamericana debía pasar de Oriente Cercano al Asia Oriental. También proyectaba la necesidad de generar una alianza similar a la de la OTAN para el Pacífico, que pueda incluir al océano Índico, esto es, fundamentalmente a la India, operativizada por el USINDOPACOM.

Desde esta mirada, las fuerzas globalistas apostaban a dos instrumentos claves. El Tratado Trans-Pacífico (TPP por sus siglas en inglés) y la Asociación Transatlántica para el Comercio y la Inversión (TTIP por sus siglas en inglés). El TPP tendría entonces un importante impacto 
geopolítico en cuanto a la distribución del poder en Asia-Pacífico, en tanto el interés de los Estados Unidos era sostener un equilibrio favorable en dicha región y contener/rodear a China. De allí la insistencia en "proteger" a estados como Filipinas, Vietnam o Taiwán de la gran dependencia de la economía china, para que no pierdan su diplomacia independiente y su influencia política.

En el caso del TTIP, el acuerdo para avanzar en la periferia occidental de Eurasia junto con la OTAN, la cuestión de fondo es si predomina el atlantismo, reforzando la posición del globalismo. Las amenazas euroasiáticas, la situación de crisis del orden mundial y los nuevos desafíos de las potencias emergentes aparecen insistentemente en los discursos a favor del TTIP por parte de los atlantistas globalistas. En este sentido, en un discurso en Estocolmo, Michael Froman (Secretario de Comercio de Estados Unidos), advirtió que no había "Plan B" si las conversaciones del TTIP no concluyeran durante el año 2016. Y agregaba: "O trabajamos juntos para ayudarnos a establecer las reglas del mundo o dejamos ese papel a otros." (Financial Times, 2016). Según observa en un artículo en Foreign Policy el analista, ex almirante de los Estados Unidos y comandante supremo de la OTAN, James Stavridis (2014), avanzar con el TTIP implicaría: “...unir Europa a los Estados Unidos, lo que daña la influencia de Rusia. El TTIP es un acuerdo razonable por motivos económicos, en términos generales. Pero también tiene un enorme valor real en el ámbito geopolítico."

De concretarse el TPP y el TTIP las fuerzas globalistas, cuyo núcleo fundamental es la territorialidad anglosajona, podrían cimentar una base territorial de 51 países con 1,6 mil millones de personas y dos tercios del PIB mundial, contando con una masa crítica importante de poder para atravesar favorablemente la lucha por la reconfiguración del orden mundial. Ello consolidaría algo crucial: la necesidad de mantener el control de las periferias occidental y oriental de Eurasia para debilitar el desarrollo de un bloque Euroasiático y se reforzaría una Europa alineada en el Atlántico, China quedaría "contenida" en su expansión e influencia regional y global, y Rusia quedaría más aislada. Mientras tanto, en América Latina avanzaría la Alianza del Pacífico -forma regional del TPP-y los acuerdos de libre comercio entre la UE y el MERCOSUR, bajo el paradigma del regionalismo abierto en detrimento de los intentos de constitución de un polo de poder regional. Cabe destacar que dentro de esta estrategia un elemento importante era el ingreso de Ucrania a la Unión Europea y de ahí al TTIP y a la OTAN. La Guerra Civil en dicho país de Europa del Este junto con el referéndum en la península de Crimea en marzo 2014, que formalizó 
su pertenencia a Rusia, marcó un límite a la geoestrategia globalista. También se produjo un límite por parte de China, como veremos más adelante, con el lanzamiento de la llamada "Nueva Ruta de la Seda" en 2013, la profundización de sus alianzas con Rusia y la progresiva construcción de alianzas euroasiáticas anti-hegemónicas. A partir de estos hechos, se generaliza la guerra híbrida -deviniendo mundial al involucrar a las principales potencias- en la medida que la crisis de hegemonía va acercándose a la etapa de caos sistémico. ${ }^{9}$

A partir del Brexit y luego con el triunfo de Donald Trump sobre Hillary Clinton, las fuerzas globalistas obtuvieron una gran derrota política en sus propios territorios. Ello acompañó al impasse de la globalización económica que comienza en 2010, cuando se agotó la fórmula según la cual por cada punto de crecimiento del PIB crecían dos puntos el comercio exterior y tres puntos la inversión extranjera directa.

Ya en la campaña presidencial de 2016 podíamos observar que la Iucha política en los Estados Unidos, inherentemente entrelazada con la crisis que transitamos, manifiesta una situación de empate hegemónico entre fracciones/fuerzas dominantes. Esto se expresa en profundas polarizaciones en torno a todos los temas que hacen a las construcción de un proyecto político estratégico: a) la guerra en Irak y la estrategia en Medio Oriente; b) el papel y poder de los organismos e instituciones multilaterales (FMI, BM, OMC, etc.) en relación al papel y poder del Estado de los Estados Unidos (unipolarismo unilateral vs unipolarismo multilateral); c) la estrategia para el enfrentamiento con las potencias/polos de poder emergentes regionales y globales; d) los acuerdos multilaterales de comercio, inversión y regulación económica transnacional (TPP, TTIP, NAFTA); e) las reformas en la regulación del sistema financiero; f) el valor de la tasa de interés de referencia de la Reserva Federal y su política monetaria general; g) la cuestión del cambio climático; h) La apuesta por las guerras híbridas o por las guerras convencionales, etc. Y estas polarizaciones atraviesan el debate intelectual, articulando de forma diversa a las distintas perspectivas teóricas e incluso fracturando dichas perspectivas.

Lo que no deja de haber un acuerdo general en la casi totalidad del llamado establishment es en mantener el dominio unipolar y en este sentido, enfrentar en conjunto a los polos de poder emergentes que desafían esta situación, especialmente a China, como también a Rusia, y mantener a los aliados subordinados. Es decir, comparten los tres grandes

\footnotetext{
${ }^{9}$ El concepto de guerra Híbrida lo trabajamos con mayor profundidad en Merino (2020) siguiendo un conjunto
} de autores como Joseph Nye, Andrew Koribko, Qiao Liang y Wang Xiangsui, entre otros. 
imperativos de la geoestrategia imperial: impedir choques entre vasallos y mantener su dependencia en seguridad, mantener a los tributarios obedientes y protegidos e impedir la unión de los bárbaros (Brzezinski, 1998). Sin embargo, difieren en el cómo, lo cual tiene raíces estructurales. Por otro lado, como dichas pujas se siguen condensando y a la vez unificando en el Estado, que expresa el estado de las relaciones de fuerza, se produce una resultante política particular con continuidades estratégicas. Pero a la vez, esto hace que dentro del mismo Estado haya múltiples políticas contradictorias y se encuentre también polarizada la burocracia, dando lugar a una intensa puja de palacio.

\section{Trump y el retorno al imperialismo unilateral}

El triunfo de Donald Trump indica un momento cualitativamente superior de la puja de poder en los Estados Unidos y expresa la reacción de un conjunto de sectores que se ven amenazados o perjudicados en el proceso de globalización (fase específica del proceso histórico de internacionalización del sistema-mundo), agudizada por el declive más pronunciado de los Estados Unidos y la crisis capitalista que exacerba la Iucha entre capitales y afecta a importantes capas de trabajadores y fracciones empresariales. Por eso, Trump fue más allá de la agenda clásica conservadora y neoliberal de la élite del Partido Republicano, incorporando mayores elementos del nacionalismo económico industrial y un discurso anti-establishment. Trump se posicionó claramente como partidario del Brexit y se manifestó contra el NAFTA o TLCAN, contra el TPP y el TTIP, procurando llevar a una relación bilateral las relaciones comerciales, para imponer el peso de la economía estadounidense, su poder político arbitrario y evitar las relaciones de competencia "perjudiciales" para los grupos y ramas retrasadas de Estados Unidos (especialmente con respecto a capitales de países aliados), agudizando las prácticas proteccionistas. ${ }^{10}$

Por otro lado, el gobierno de Trump retorna la política exterior del "eje del mal" definida por Bush y los neoconservadores, en donde en su momento se incluía a Irán, Irak, Corea del Norte, Libia, Siria y Cuba, a los que luego se agregaron Bielorrusia, Birmania y Zimbabwe. El desarrollo de

\footnotetext{
${ }^{10}$ Las dos caras de este proceso de "globalización" son evidentes: por un lado, desde mediados de los 80' -a partir de las reformas neoliberales, la globalización financiera, la transnacionalización y los saltos tecnológicos- se incrementan extraordinariamente las ganancias de las empresas estadounidenses y crecen en particular de forma extraordinaria las ganancias obtenidas en otros países en relación a las ganancias obtenidas en los Estados Unidos, las cuales pasan de 50.000 millones de dólares a mediados de los ochenta para llegar a 500.000 millones de dólares en 2008, superando la masa de ganancias internas. En contraste, este proceso se traduce en Estados Unidos en la quiebra de 60.000 empresas, en un bajo crecimiento de la productividad de las pymes entre 2010 y 2017 en relación al núcleo más dinámico, en la destrucción de 5 millones de puestos de trabajo industriales en los últimos 15 años, en la caída de la participación de los salarios sobre el PIB del 48,7\% (1980) al 42,7\% (2015) y en la aparición de fenómenos de "sobreexplotación" de la fuerza de trabajo propios de la periferia, configurando un contrastante paisaje de destrucción creativa de los "molinos satánicos del capital".
} 
posibles guerras en dichos territorios secundarios tiene como objetivo conquistar posiciones claves y/o impedir el avance de potencias rivales, a la vez que alimentar la economía doméstica de los Estados Unidos mediante el complejo industrial militar, haciendo uso del monopolio del dólar para su financiamiento. Además, presenta un rotundo apoyo a la geoestrategia neoconservadora del gobierno israelí de Netanyahu (expresado simbólicamente en el traslado de la embajada de los Estados Unidos a Jerusalén, entre otras cuestiones), que implica avanzar sin miramientos en la conquista de Palestina y en la construcción del Gran Israel para desequilibrar el juego de las potencias regionales. También se observa el retorno al recrudecimiento de la posición contra Irán como el gran enemigo a vencer en la llave geopolítica del Gran Medio Oriente y, por ello, la búsqueda por todos los medios de destruir el acuerdo nuclear entre dicho país y las principales potencias mundiales.

Pero a su vez, también en este plano se produce un cambio con respecto al gobierno de Bush, en línea con la nueva situación mundial: el cambio en la doctrina militar, donde vuelve a ser central el enfrentamiento con estados rivales que amenazan el dominio de Estados Unidos en el mundo, especialmente China y Rusia. Además, con el gobierno de Trump, se exacerba el unilateralismo, como se observa en el caso de la ruptura de los acuerdos con Irán y de los acuerdos con Cuba, el retiro del Acuerdo de París, las tensiones en la OTAN, la guerra comercial que involucra también a sus tradicionales aliados (Merino, 2019), el cuestionamiento y crisis de la OMC, el traslado de la embajada a Jerusalén y el retiro de la UNESCO. Lo paradójico es que el orden mundial construido dominantemente por Estados Unidos es cuestionado por las propias fuerzas que pugnan en Estados Unidos: los globalistas porque entienden que ya quedó obsoleto y que resulta insuficiente para contener a las potencias emergentes y a la nueva realidad del poder mundial, mientras los "americanistas" y nacionalistas entienden que dicho orden se les volvió en contra y es un obstáculo en la estrategia de recuperar la primacía.

Para América Latina, el trumpismo parecería retomar la apuesta por el control hegemónico directo de la región, como área prioritaria de influencia directa para el enfrentamiento con otros bloques de poder ${ }^{11}$. En este sentido, el vicepresidente Mike Pence ha reivindicado posturas injerencistas propias de la Doctrina Monroe ("América para Washington") y el ex consejero de Seguridad Nacional, John Bolton, llegó a afirmar que dicha doctrina está "vivita y coleando" (Sputnik, 2019). Estas figuras, junto a la de Pompeo, ligadas a los neoconservadores, han exacerbado las

\footnotetext{
$"$ Para un análisis detallado de esta afirmación ver, entre otros materiales, el libro "Estados Unidos contra el mundo: Trump y la nueva geopolítica", editado por Castorena Sánchez, Gandásegui y Morgenfeld (2018).
} 
presiones directas contra Cuba, Venezuela y Nicaragua. Por otra parte, el propio Jefe del Comando Sur, el almirante Kurt Tidd, ha señalado insistentemente y con especial preocupación la influencia de Pekín en América Latina (como también de Rusia y de Irán) y su avance en el plano geoeconómico (principal socio comercial de Suramérica), identificando sus inversiones como una amenaza para la seguridad nacional de los Estados Unidos. $^{12}$ En este sentido, Washington pone en práctica de forma explícita la política de áreas de influencia. Si bien, como observa Borón (2014), siempre resulta prioritaria la región para el imperialismo estadounidense, y como señala Suárez Salazar (2017) con Barack Obama comienza una contraofensiva para recuperar la influencia en Nuestra América -que nosotros identificamos claramente a partir del surgimiento de la Alianza del Pacífico en 2011, en pleno desarrollo, durante una nueva etapa de la crisis del orden mundial, de los antagonismos entre las fuerzas unipolares y las fuerzas multipolares (Merino, 2014) - , se pueden identificar un cambio importante de estrategia a partir de Trump. Para ejemplificar, basta tomar el caso de Cuba y observar los acuerdos y la política de "descongelamiento" de la era Obama, en comparación con la política de eje del mal, bloqueo absoluto y sanciones del gobierno de Trump, que podemos resumir como de "palo sin zanahoria", que profundizamos en otros trabajos (Merino, 2019). Se trata de dos estrategias imperiales bien distintas, aunque compartan en líneas generales los grandes objetivos geopolíticos, como también se ve en el caso de Irán.

En el plano político, el "americanismo" reivindica un retorno a la soberanía del Estado-nacional y el fortalecimiento unilateral del polo de poder angloamericano -junto al Reino Unido, Canadá, Australia, Nueva Zelanda más Israel- por lo que se vuelve muy importante el Brexit y el estrechamiento de los lazos económicos entre dichos países. El reforzamiento de lo que podemos llamar un "angloamericanismo" unilateral en lo geopolítico, enfrentado al unipolarismo multilateral, se corresponde con un "anglosajonismo" identitario como horizonte estratégico, enfrentado a la lógica multicultural del globalismo. En su forma dominante se manifiesta como una exacerbación de la identidad blanca, anglosajona y protestante (en inglés los WASP) y sirve de argamasa al imperialismo retrasado, traduciéndose en la política como una suerte de nacionalismo étnico.

Estos cambios que expresa Trump tienen su anclaje económico y social. Así como el globalismo en el plano político tiende a institucionalizar

${ }^{12}$ Audición de Kurt Tidd ante la Comisión de Servicios de las Fuerzas Armadas del Senado de Estados Unidos, 15 de febrero de 2018 
el poder occidental transnacionalizado $y$, en el plano cultural, el multiculturalismo (organizado bajo la perspectiva posmoderna del liberalismo occidental) erosiona las identidades nacionales en los países centrales; en lo económico el globalismo reconfigura el viejo centro, desarrolla nuevos centros-nodos globales y crea nuevas periferias en los viejos territorios centrales. En este sentido, emerge como nueva periferia el ahora llamado cinturón del óxido en Estados Unidos, en lo que antes era el corazón industrial del medio-oeste, como también en el Midland británico, cuyos votantes se volcaron mayoritariamente por Trump y el Brexit. Los capitales industriales centrados en el mercado interno que dominan estos territorios, menos competitivos en términos internacionales, se ven sucumbidos frente a la intensificación de la competencia y la concurrencia de capitales. Además, el avance industrial de China, que ya disputa en los primeros niveles mundiales de algunas ramas productivas y en el control de los flujos globales (dinero, mercancías, datos), así como también los saltos tecnológico-productivos de los capitales del propio Norte Global (alemanes, japoneses, etc.), agudizan las presiones competitivas y achican el espacio para la acumulación global del capital, exacerbando las luchas de competencia y concurrencia entre capitales. Esto se refuerza en tanto que al Estado norteamericano le cuesta mantener las condiciones de monopolio. Por ello, estas fuerzas contrarias al globalismo también rechazan el TPP y el TTIP y apuntan contra sus propios aliados, a quienes demandan subordinación unilateral, agudizando necesariamente las pujas al interior del Norte Global.

La lucha entre capitales y los procesos de crisis alimentan las pujas político-estratégicas (modelos de capitalismo en pugna, geoestrategias en pugna, identidades y cosmovisiones en pugna, etc.) y constituyen un elemento central para analizar las fisuras en Estados Unidos y el polo angloamericano. En este sentido, no resulta casual que uno de los principales apoyos de Trump provenga de los industriales del carbón y del complejo sidero-metalúrgico estadounidense. Dan Dimiccio, ex CEO de la siderúrgica Nucor fue uno de los principales asesores de Trump en economía y política comercial. Mientras que Robert Lighthizer, nombrado por Trump como Representante Comercial de los Estados Unidos, tiene una larga trayectoria representando a la industria siderúrgica estadounidense y ha sido un promotor central del giro proteccionista en importantes sectores del Partido Republicano, a la vez que protagonizó las batallas siderúrgicas contra Japón décadas atrás.

Refuerzan esta presencia industrial en el gobierno de Trump la figura de Mike Pompeo como jefe de gabinete, estrechamente ligado con las 
industrias Koch, así como el Secretario de Defensa Mark Thomas Esper, quien fuera vicepresidente del área de relaciones gubernamentales de Raytheon (el mayor contratante de defensa de Estados Unidos). A su vez, Esper sustituyó a Patrick Shanahan, quien fuera directivo entre 1986 y 2017 de la empresa aeroespacial Boeing, estrechamente ligada al Pentágono.

No resulta extraño, por eso, que una de las primeras medidas de Trump fuera ordenar al Departamento de Comercio que lleve a cabo una investigación para determinar si las importaciones de acero, particularmente las procedentes de China, son una amenaza para la seguridad nacional, en línea con sus promesas proteccionistas. Flanqueado por representantes de la industria siderúrgica, Trump afirmó: "El acero es fundamental tanto para nuestra economía como para nuestras Fuerzas Armadas. Esta no es un área donde podamos permitirnos depender de países extranjeros" (EFE, 2017), refiriéndose que proteger dicha industria es una cuestión de seguridad nacional. Es decir, lo que se impuso como dominante en el poder ejecutivo con Trump es un grupo de poder clave con fuerte base en complejo industrial-militar nacional.

Otro punto referido a la agenda económica y a las pugnas en la cúpula empresarial es sobre el impuesto fronterizo o un impuesto a las importaciones, que el jefe de gabinete de Trump anunció que se impulsaría como parte del proyecto de reforma fiscal. Como se señala en Merino (2019), un mes antes de dicha declaración, 16 grandes compañías industriales exportadoras emitieron un comunicado en el cual instan al gobierno a adoptar el impuesto a las importaciones. La carta en respaldo a un impuesto fronterizo fue firmada por los presidentes ejecutivos de Boeing, CoorsTek, Caterpillar, Dow Chemical, Celanese, GE, Celgene, Eli Lilly and Co, Raytheon, Merck \& Co Inc, S\&P Global Inc, Oracle, United Technologies, Pfizer Inc y Varian Medical Systems Inc. Estas compañías poseen una fuerte base productiva en los Estados Unidos, alguna de ellas son grandes contratistas del Pentágono y se ven fuertemente afectadas en sus ramas por la competencia global, mientras que el Estado norteamericano ya no puede garantizar monopolios mundiales excluyentes, disputados por otros centros del Norte Global y China.

\section{La guerra comercial}

Trump ha declarado la guerra comercial al mundo, visibilizando la pérdida del dominio en el plano productivo-industrial de los Estados Unidos. Con ello, puso en marcha una profundización de la política proteccionista y un bilateralismo comercial que busca proteger a las 
fracciones de capital y ramas retrasadas en la economía global y fortalecer la producción industrial de Estados Unidos frente a China, pero también frente a aliados como Alemania, Japón o México. Los objetivos son reequilibrar el déficit comercial -agravado, a su vez, por las políticas de híper-estímulos de la administración Trump y el keynesianismo militar-y, sobre todo, reforzar la "seguridad nacional", ya que la industria es la base de la defensa. Por otra parte, busca asegurar los monopolios tecnológicos estadounidenses que todavía poseen frente a sus rivales, aspecto central en el poder mundial (AMIN, 1998). En el discurso del Estado de la Unión de 2018, Trump fue particularmente enfático en la promesa sobre importantes inversiones en las próximas industrias tecnológicas de importancia estratégica.

Luego del primer año de gobierno de Trump, el déficit comercial subió entre 2016 a 2017. Con China fue de 375.100 millones de dólares (Merino, 2019). Frente a ello, el gobierno de Trump demandó a China una reducción de 100.000 millones de dólares en sus exportaciones, tratando de imitar al gobierno de Reagan en los ochenta, cuando se "obligó" a Japón a auto-limitar sus exportaciones hacia los Estados Unidos, como también a subordinarse a la política monetaria de la Reserva Federal y a financiar al Tesoro estadounidense. Allí hay que buscar algunas de las razones fundamentales del estancamiento del país del sol naciente, que lleva más de un cuarto de siglo y del cual todavía no puede salir. El problema es que China no es un protectorado político-militar estadounidense como Japón, su escala es mucho mayor (ya superó a Estados Unidos en PIB a paridad de poder adquisitivo) y la alianza con Rusia fortalece su posición político-estratégica en Eurasia.

La razón central del enfrentamiento comercial con China es detener su drástico ascenso global. Para ello, el trumpismo considera que debe frenar el "alarmante" plan de desarrollo tecnológico Made in China 2025, que tiene entre sus principales objetivos solucionar el retraso relativo en algunas ramas tecnológicas fundamentales como robótica, semiconductores e industria aeroespacial, y ampliar el liderazgo en otras, como inteligencia artificial y autos eléctricos. De concretarse el plan, aunque sea de forma parcial, se terminaría de quebrar definitivamente la relación centro-semiperiferia del gigante asiático con el Norte Global, poniendo totalmente en crisis la división internacional del trabajo y las jerarquías en la economía mundial, a la vez que planteando un desafío sistémico: que un país con la quinta parte de la población planetaria se convierta en centro desarrollado. 
Lo que está en juego para el trumpismo es la primacía geopolítica a largo plazo de Estados Unidos. Así lo expresa el intelectual y funcionario de la administración Trump, Peter Navarro, en su libro del año 2011 Death by China: Confronting the Dragon - A Global Call to Action. La primacía estadounidense sólo puede lograrse a través de un equivalente del siglo XXI del Informe sobre Manufacturas de Alexander Hamilton de 1791, en donde se decidan qué industrias son esenciales para la seguridad nacional, junto con una política tecnológica-industrial planificada para asegurar de que esas industrias vitales permanezcan en el país, complementadas por un fuerte proteccionismo y una guerra económica con los rivales. Acá aparece el nacionalismo económico de Pinkerton que mencionamos al comienzo, combinado con el neoconservadurismo.

La guerra comercial tiene como trasfondo la creciente "guerra" económica, en la cual se agudizan las luchas entre capitales mediadas por los estados. El contexto de bajo crecimiento en el Norte Global desde la crisis financiera global de 2007-2008, profundiza esta situación y su perspectiva. Al haber bajo crecimiento la acumulación de los capitales particulares se da en detrimento de los más retrasados y de los trabajadores, poniéndose en juego mecanismos de "acumulación por desposesión", utilizando la imagen de Harvey (2004). Los capitales globales acumulan en los territorios emergentes que crecen (particularmente China), posibilidad que no tienen los capitales dependientes de las economías nacionales estancadas. Pero a su vez, el proceso conocido como globalización económica, por el cual el comercio mundial se expandió al doble del PIB mundial y la inversión extranjera directa al triple durante casi 30 años, se detuvo con la crisis que estalló en 2008, poniéndose de manifiesto un límite estructural.

El poco crecimiento que hubo en el Norte global en los últimos años se produjo gracias a las políticas híper-expansivas de los Bancos Centrales. Esa política está encontrando sus límites, creando una enorme burbuja en los bonos públicos. Se observa una crisis próxima, que puede desplegarse sobre un ciclo de crisis mucho más profundo debido al agotamiento del ciclo expansivo (A) de Kondrátiev iniciado en 1994 y a las tendencias estructurales de la economía mundial. Ello pronostica una agudización de las luchas económicas que, de acuerdo a cómo se desarrolle y se "resuelva", va a alimentar la grieta en los Estados Unidos, la guerra económica a nivel mundial y la lucha entre polos de poder en todos los planos.

\section{Ascenso de China}


El ascenso de China y su dinamismo económico no son reductibles, entendemos, a la adhesión por parte de China al capitalismo neoliberal y/o como epifenómeno de la globalización y la deslocalización productiva del Norte Global, tal como se piensa en buena parte de la academia occidental. Su ascenso está estrechamente relacionado, en primer lugar, a la obtención de importantes niveles de autonomía y fortaleza política-militar (soberanía) y cierto bienestar básico en materia de salud y educación producto de la revolución de 1949, a partir de la cual se produjo un crecimiento al 6\% anual entre dicho año y 1978. Luego se produce el despegue con las reformas iniciadas 1978 que atrajo los capitales de la diáspora china (Taiwán, Singapur, Hong Kong), absorbió niveles inferiores del proceso de tercerización en el Asia-Pacífico encabezado por Japón y desarrolló importantes entramados económicos comunales y estatales. Más tarde, absorbió grandes volúmenes capitales de occidente bajo sus propias condiciones (necesidades productivas planificadas, transferencias tecnológicas, restricciones a la extraversión de ganancias) para devenir finalmente en la gran plataforma industrial mundial. Lo hizo desde un proyecto propio, a partir de su historia y características propias -centrado en el crecimiento de la productividad más que por la inversión de capital (Zhu, 2012) - y con una singular combinación o hibridación de modos de producción, aprovechando la propia necesidad expansiva del capital del Norte Global.

El modelo de desarrollo híbrido de China no califica dentro del marco capitalista occidental clásico ya que se mantiene propiedad colectiva de la tierra, los núcleos centrales de la economía están en manos de grandes empresas estratégicas estatales y existe un fuerte desarrollo de las empresas de pueblos y aldeas de propiedad colectivas -TVE- que son las principales empleadoras de la economía (Amin, 2013). Por lo tanto, la presente transición histórico-espacial no se trataría (si es que se produce) de un traspaso del poder desde un estado occidental y capitalista a otro más fuerte y dinámico, para iniciar un nuevo ciclo hegemónico del sistema mundo moderno. Es más, el propio ascenso de China invita a consolidar la pregunta de si existe una tendencia definitiva y estructural sobre el fin de la primacía de las fuerzas fundamentales de occidente en el sistema mundial y, especialmente, su supremacía protagonizada por el mundo anglosajón a partir de lo que se denomina la gran divergencia, con la combinación de revolución industrial, expansión capitalista, colonialismo y supremacía militar (Arrighi, 2007). Lo cual está articulado con la formulación de Wallerstein (2006) acerca de que estamos frente a una situación de límite estructural para la supervivencia del sistema mundial moderno como tal, lo que abre la pregunta de si estamos en presencia de 
una crisis definitiva de la modernidad capitalista como sistema histórico y en qué medida el ascenso de China y Asia Pacífico es parte de ese proceso.

Como señalamos al comienzo del trabajo, en el final de la belle époque neoliberal unipolar, China comienza a mostrar signos de su devenir con nuevo polo de poder desafiante del orden mundial. Un momento clave del ascenso chino fue la crisis de 2008 que golpeó al Norte Global y expuso todas sus contradicciones. A partir de allí, China deja de financiar al Tesoro estadounidense y su déficit estructural, mediante la compra de deuda: si China entre 2005 y 2008 compró el 49,3\% de los títulos públicos del Tesoro, en 2009, frente a la baja en el crecimiento, adquirió el 19,6\%, mientras que el resto fue a impulsar la demanda interna e impidió una recesión inyectando en su economía fondos por 500.000 millones de dólares (Martins, 2011). Esto diferencia profundamente a China del Japón de los años ochenta que, en tanto "protectorado" militar norteamericano, aceptó las políticas deflacionistas del "dólar fuerte", financiar el déficit estadounidense y hasta "auto-limitarse" en sus exportaciones a los Estados Unidos. Algo parecido a lo que demanda Donald Trump en la actualidad pero que China se resiste a aceptar.

Por otro lado, otra de las respuestas a partir de 2009 fue la convocatoria a la primera reunión de los BRIC, en la cual comenzó a delinearse un espacio de los principales poderes emergentes -ya no sólo mercados emergentes. Allí se puso sobre la mesa, entre otras cuestiones, la necesidad de avanzar en una alternativa colectiva al dólar, un desafío al corazón de la hegemonía estadounidense.

En cuanto al avance económico de China -cuyo PIB medido por la paridad del poder adquisitivo ya superó al de Estados Unidos en más de un 20\% y, por otro lado, superó a la Eurozona como mayor sistema bancario del mundo- tres cuestiones resultan claves a partir de la crisis de 2008:

1) la adquisición de empresas en el extranjero e inversiones en áreas críticas para sus necesidades de desarrollo, vinculadas fundamentalmente a energía, alimentos e infraestructura: compra por parte de la comercializadora de granos estatal china COFCO de Noble Group y de la cerealera Nidera (de capitales holandeses y argentinos), con lo que China se consolidó como uno de los principales jugadores en el monopolio de la comercialización de granos. Por otro lado, Bright Food, del gobierno municipal de Shanghái, adquirió la marca británica Weetabix y en 2015 compró la empresa catalana Miquel Alimentación. Se debe destacar también, entre otras adquisiciones, la compra del gigante biotecnológico 
de origen suizo Syngenta por $\mathbf{4 3 . 0 0 0 ~ m i l l o n e s ~ d e ~ d o ́ l a r e s ~ q u e ~ l e ~ p e r m i t i o ́ ~ e l ~}$ acceso a tecnología de punta en materia agroalimentaria. O la compra de Volvo por parte de la china Geely que le dio acceso a tecnología automotriz de punta. El intento reciente de comprar empresas de semiconductores de los Estados Unidos, con el fin de desarrollarse en esa rama tecnológica en la cual China es fuertemente dependiente, fue prohibido por las autoridades norteamericanas.

2) La internacionalización del yuan (renminbi): creciente uso del yuan como moneda de reserva de distintos bancos centrales, así como acuerdos con Bancos Centrales de préstamos en yuanes para fortalecer las reservas (swaps cambiarios bilaterales). El Consejo Mundial del Oro certificó que este año 2016 China y Rusia se han vuelto a convertir, por sexto año consecutivo, en los principales compradores de oro de todo el mundo, incrementando de forma sustancial sus reservas de este metal. Ello está en estrecha relación con la hipótesis de apuntalar sus monedas retornando a alguna forma de patrón oro, en detrimento del dólar. También el lanzamiento de un mercado de petróleo en yuanes en 2018 refuerza dicha política de internacionalización monetaria y golpea el tan preciado monopolio del petrodólar, base del sistema monetario desde 1971. Esto se articula con la creación de nuevos instrumentos financieros internacionales como el Banco Asiático de Inversión en Infraestructura y el lanzamiento del Nuevo Banco de Desarrollo de los BRICS junto a un Fondo (Acuerdo de Reservas de Contingencia) en la cumbre de Fortaleza, Brasil, en 2014. Dicha arquitectura financiera paraleliza a la del Norte Global, centrada en el FMI y el BM, y comandada por Estados Unidos y el Reino Unido.

3) El avance hacia la complejidad económica y el desarrollo de tecnología, en donde China ya acortó buena parte de la desventaja con los centros del Norte Global e incluso comienza a ser vanguardia en algunos sectores. De acuerdo a datos del Banco Mundial (2020), China es el mayor exportador de bienes del mundo, donde hacia el año 2015 un 94,4\% son bienes manufacturados, en un $48 \%$ son máquinas, y de los bienes manufacturados el 25,6\% son de alta tecnología. Por otro parte, cerca de 731 millones de ciudadanos chinos estaban online en 2016 y 95\% de ellos accedían a Internet con sus teléfonos celulares. Esto brinda una masa de información digital -Big Data- que es varias veces mayor que la norteamericana. Es a partir del cruce con esta gigantesca base que despliega su liderazgo en la inteligencia artificial (Al), la tecnología estratégica de la nueva revolución industrial en curso. Además, Shenzhen o Beijing disputan con Silicon Valley y otros centros del Norte Global el carácter de nodo estratégico de alta tecnología de la economía mundial. 
De hecho, Shenzhen, Guangdong, Hong Kong y Macao forman parte del Área de la Gran Bahía (AGB) en el delta del río Perla, una megalópolis de 70 millones de habitantes por donde se producen los componentes del 90\% de los artefactos electrónicos que se consumen en todo el mundo. En este sentido, también debe mencionarse el plan de desarrollo tecnológico e industrial "Made in China 2025", que busca terminar con la brecha todavía existente con el norte global en algunas ramas tecnológicas más avanzadas (semiconductores, robótica, tecnología aeroespacial), así como consolidar el liderazgo en otras.

De la mano de su crecimiento económico, China desarrolla su complejo militar y moderniza a grandes velocidades sus Fuerzas Armadas. Ello, junto al poder en dicho plano de Rusia, pone en jaque el monopolio estadounidense. En este sentido, el presupuesto militar de China ha ido incrementándose progresivamente en los últimos años, llegando en 2014 a los 130.000 millones de dólares y superando los 220.000 millones en 2017. Posee el segundo presupuesto militar a nivel mundial, aunque muy por debajo de los EEUU ${ }^{13}$. Uno de los aspectos centrales del desarrollo militar chino tiene que ver con la disputa por el control del Pacífico. En este escenario, China profundiza la construcción de portaaviones, submarinos y misiles, fortaleciendo la capacidad estratégica de su complejo industrial-militar, lo cual genera alarma en las autoridades estadounidenses según se lee en informes oficiales. ${ }^{14}$ Según el general chino Sun Sijing, "El aumento de dos cifras del gasto de defensa a algunos puede parecerles demasiado, pero en el desarrollo del complejo militar todavía estamos muy por detrás (...) Nuestras empresas han tomado el mercado mundial y tenemos qué y a quién defender" ${ }^{\prime 15}$. La situación en la zona del mar de China se agrava por la agudización de las tensiones globales y los conflictos geoestratégicos en torno a las islas Senkaku/Diaoyu, el archipiélago Spratly/Nansha Qundao y las islas Paracelso, además del histórico conflicto de las Coreas. El Mar del Sur de China es esencial para la economía de Asia. Una tercera parte de los

\footnotetext{
${ }^{13}$ El gasto militar mundial aumentó en 2017 a su nivel más alto desde el fin de la Guerra Fría, en un año en el que Estados Unidos, China y Arabia Saudita fueron los que más dinero destinaron a la defensa, según un estudio del Instituto Internacional de Estocolmo para la Investigación de la Paz (SIPRI, por sus siglas en inglés). Estados Unidos concentra el 35\% del gasto militar global, China 13\%, Arabia Saudita 4\%, Rusia 3,8 y la India 3,7\% (La Nación, 3 de mayo de 2018).

14 "China's navy is viewed as posing a major challenge to the U.S. Navy's ability to achieve and maintain wartime control of blue-water ocean areas in the Western Pacific" (Congressional Research Service, 2020)

${ }^{15}$ Fragmentos de la entrevista con el comisario político de la Academia de Ciencias Militares, el general Sun Sijing, que han sido divulgados al inicio de los informativos en China y luego por el canal estatal CCTV (RT, 2014).
} 
buques del mundo navegan por sus aguas, y enormes reservas de petróleo y gas yacen bajo su lecho. ${ }^{16}$

Otro plano fundamental para analizar el ascenso de China es el geopolítico, junto a sus imperativos geoestratégicos. Allí sobresale una apuesta fundamental, la llamada "Nueva Ruta de la Seda". El avance del Tratado Trans-Pacífico (TPP) durante la presidencia de Obama y la adhesión de Japón al TPP en marzo de 2013, implicó rodear a China y avanzar en la estrategia de contener su expansión y la influencia del gigante asiático en Asia Pacífico. Frente a ello, China respondió en septiembre de 2013 con la promoción de la Iniciativa del Cinturón y la Ruta -Belt and Road Initiative (BRI) - , buscando consolidar ante todo su poder en el corazón del continente Euroasiático, frente a los desafíos del 'imperio de mar'. Allí converge con una Rusia cada vez más inclinada hacia la construcción de un eje de poder anclado en el espacio euroasiático frente al avance de Estados Unidos y aliados (OTAN) en territorios considerados sensibles para sus intereses (Europa del Este, el Cáucaso, Asia Central, Siria). El BRI, impulsado por Xi Jinping en 2013, luego de sus viajes a Rusia, Bielorrusia y Kazajistán (los protagonistas de la Unión Económica Euroasiática con centro en Moscú), involucra a unos 60 países, en su mayoría en desarrollo. Allí habitan 4.400 millones de habitantes (63\% de la población mundial), se encuentran $75 \%$ de las reservas energéticas conocidas al mundo y se produce 55\% del PIB mundial. El gobierno de China tiene previsto invertir en BRI la descomunal cifra de 1,4 billones de dólares. Ya está contemplado un presupuesto de 890.000 millones de dólares, procedentes del Fondo de la Ruta de la Seda, del Nuevo Banco de Desarrollo y del Banco Asiático de Inversiones en Infraestructuras. A su vez, los bancos estatales-comerciales chinos -Bank of China, ICBC y China Construction Bank- han ofrecido más de 500 mil millones en préstamos e inversiones de activos (Parra Pérez, 2017).

Los seis corredores de BRI parecieran tener, además de sus obvias razones geoeconómicas, claras intenciones geoestratégicas: evitar los estrangulamientos al desarrollo de China y quebrar la geoestrategia angloamericana de rodear-contener a China, Rusia y aliados continentales. Ésta deja encerrada y vulnerable a China, con sus principales líneas de abastecimiento amenazadas. En este sentido, en el mapa en donde se trazan los corredores y la ruta marítima, vemos que éstos rompen los estrangulamientos de China: un tren a través de Myanmar proporciona una ruta hacia el mar que elimina el punto de congestionamiento del estrecho

\footnotetext{
${ }^{16}$ Por su parte Japón (aliado estratégico de EE UU), en lo que significó un giro histórico de su política exterior, incrementó significativamente el gasto en defensa y modificó la interpretación de su "Constitución de la Paz", para poder combatir en el extranjero y defender a sus aliados, incluso cuando Japón no sea atacado.
} 
de Malaca en Singapur (centro financiero global aliado a Occidente). Por otro lado, un corredor junto a un nuevo puerto en Pakistán proporciona acceso directo al Océano Índico y al Golfo Pérsico, desde donde sale el 40\% del Petróleo comercializado en el mundo, gran parte del cual va hacia China. ${ }^{17}$ De igual forma, tanto el corredor China-Mongolia-Rusia como el corredor Nuevo Puente Terrestre de Asia permiten una conexión directa con Europa, una salida al Mediterráneo y una integración Euroasiática continental. Ello rompe el eje-tapón que separa territorialmente Asia-Pacífico y Europa, que otorga la superioridad estratégica al polo de poder que controla el mar. Además, el importante protagonismo de Rusia permite aminorar sus posibles recelos geopolíticos con el ascenso de China. Por otra parte, el corredor Indochino aseguraría aumentar la influencia en el sureste asiático continental. El sentido estratégico de la "unificación" de Europa y Asia es que quiebra el "cordón sanitario" atlantista, cuyo control es históricamente fundamental para la geopolítica angloamericana (desde 1815), el cual va desde los países escandinavos hasta Omán, al sur de la península Arábiga, pasando por los países bálticos, Polonia y Europa del Este (incluyendo Ucrania), Turquía, Siria e Irak y Arabia Saudita.

\footnotetext{
17 Parra Pérez (2017: 8) apunta que "Cuestión importante es la profundidad del puerto de Gwadar, que permite albergar a submarinos y portaviones, convirtiéndose en un punto de referencia en la estrategia militar de China en ultramar. Esta base militar, junto con la de Djibouti, muestran el creciente interés de China por aumentar su despliegue más allá de las aguas de Asia-Pacífico, entrando en competencia con las bases militares de Estados Unidos en la región."

${ }^{18}$ Es importante señalar que el Gasoducto Nord Stream 2, que conecta de forma directa Alemania y Rusia, es otro quiebre de este "cordón sanitario" y es fuertemente rechazado por Estados Unidos. También lo es el eje Siria, Irak, Irán (dónde también se encuentran El Líbano e Israel) que conecta el mediterráneo con Asia Central y China. Por otro lado, los movimientos de Turquía (potencia media ubicada en un punto clave de la articulación continental) hacia un bloque Euroasiático constituyen una amenaza central para dicho cordón. En este sentido, también resulta clave el accionar de China en Europa Central y del Este a través del espacio "16 + 1", que equilibra la influencia de Estados Unidos en dicha región.
} 
Figura 1: Corredores de BRI

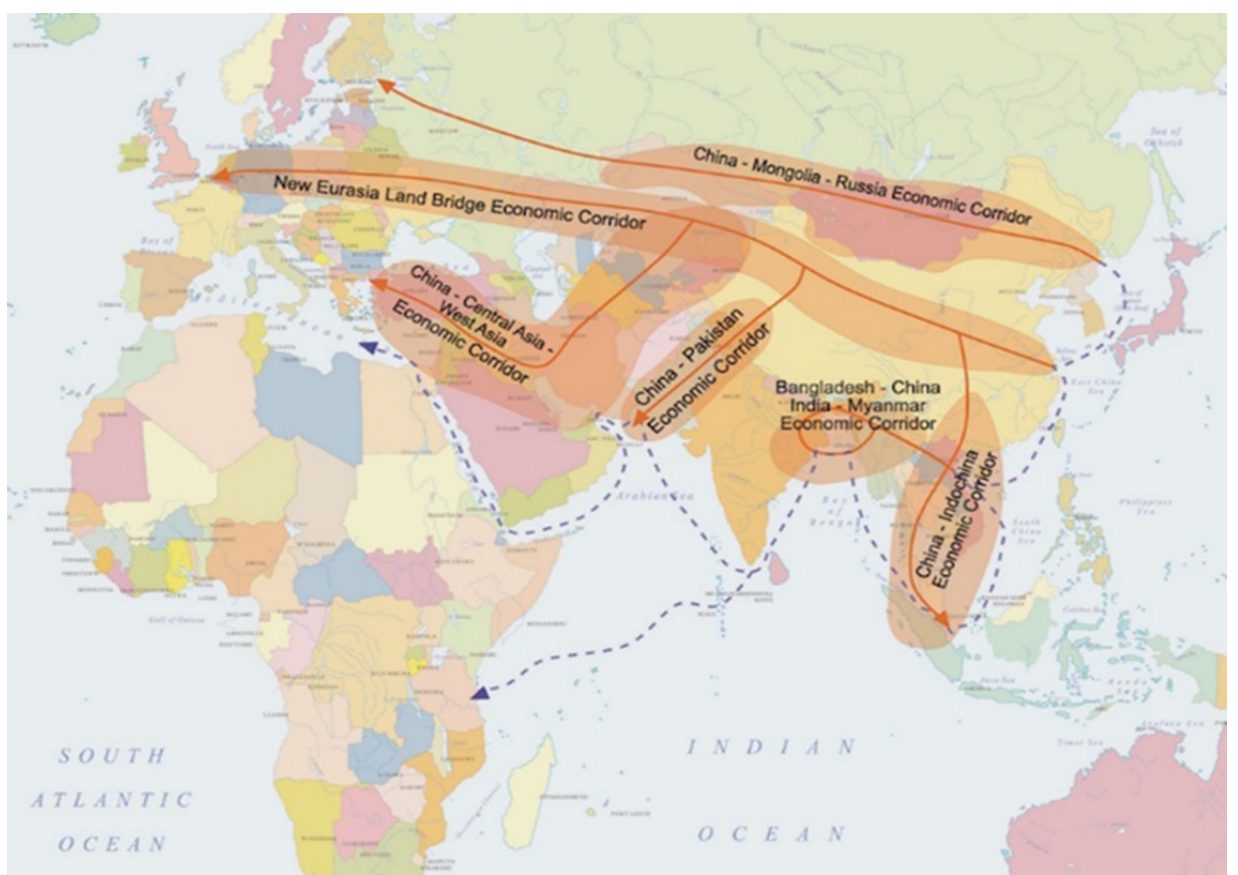

Fuente: Vivekananda International Foundation, Rashmini Koparkar.

El desarrollo de la red ferroviaria Euroasiática, para comunicar e integrar toda la masa continental, es uno de los elementos centrales que sobresalen en la propuesta de BRI y forma parte de la proyección de un gran puente terrestre euroasiático, que unifica la gran masa continental y pone en crisis el poder marítimo que ostentaron históricamente los imperios occidentales de la modernidad. De hecho, uno de los pensadores más brillantes del "imperio de mar" anglosajón, Halford Mackinder, ya había observado las implicancias de ello en el balance de poder mundial: "Hace una generación, el vapor y el canal de Suez parecían haber aumentado la movilidad del poder marítimo con relación al poder terrestre. Los ferrocarriles funcionaron principalmente como tributarios del comercio oceánico. Pero los ferrocarriles transcontinentales están ahora modificando las condiciones del poder terrestre, y en ninguna parte pueden ejercer tanto efecto como en el cerrado "corazón continental" de Eurasia (...) ¿No es la "región pivote" de la política mundial esa extensa zona de Eurasia que es inaccesible a los buques, pero que antiguamente estaba abierta a los jinetes nómadas, y está hoy a punto de ser cubierta por una red de ferrocarriles?" (Mackinder, 2010: 315-316). Además, esta proyección continental euroasiática que equilibra la superioridad marítima 
que todavía ostenta Estados Unidos, se complementa con importantes proyecciones oceánicas: el collar de perlas, la ruta del Ártico o la extensión del BRI hacia América Latina, que incluye la construcción del canal de Nicaragua -lo cual sería un parteaguas secular de la geopolítica de América Latina y el Caribe si llega a concretarse.

En términos geoeconómicos, el BRI es parte de un cambio global y significa un avance hacia la formación de un nuevo patrón de desarrollo, distinto al de la tríada y a su modelo centro-periferia. Por sus características tiende a la diversificación de los flujos de capital y de los flujos espaciales de los factores de producción, que se expanden progresiva y profundamente dentro de los hinterlands euroasiáticos (Ning; Chuankai, 2018). El BRI implica dar forma a una transformación radical del mundo tal y como está configurado desde el siglo XIX, con centro en el Atlántico y en Occidente, y la versión del siglo XX de este mundo, especialmente a partir de la posguerra: con centro en los Estados Unidos, desde donde se coordinan los otros dos centros económicos del sistema mundial capitalista: Europa occidental y Japón/Asia Pacífico. Desde la perspectiva del BRI el centro geoeconómico es China que, integrando Eurasia y sus periferias dinámicas oriental y occidental, deja en un papel subordinado a los Estados Unidos y consolida su máxima estratégica de construcción de poder global: "el reino medio está (debe estar) en el centro de todo lo que brilla bajo el cielo". Concepción estratégica que difiere del imperialismo militarista de tipo occidental.

El BRI se complementa con otra iniciativa fundamental, que se solapa con el caído TPP, pero también procura equilibrar desde el plano económico la insistente búsqueda de alianzas político militares más profundas por parte de Estados Unidos en la región de Asia Pacífico y el Índico, a través del ya mencionado USINDOPACOM. Esta otra iniciativa es la Asociación Económica Integral Regional (conocida como RCEP por sus siglas en inglés), que integra a los diez países de la ASEAN (Brunei, Camboya, Indonesia, Laos, Malasia, Myanmar, Filipinas, Singapur, Tailandia, Vietnam) y los seis estados del Pacífico y el Índico con los que la ASEAN tiene acuerdos de libre comercio existentes (Australia, China, India, Japón, Corea del Sur y Nueva Zelanda. Las negociaciones comenzaron en 2012, como contracara al avance del TPP y con normas distintas a las que pretendían imponer las fuerzas globalistas a través de dicho acuerdo (por ejemplo, en materia de propiedad intelectual), y han avanzado grandes pasos después de que Trump retiró a Estados Unidos del TPP. Esta iniciativa, de concretarse definitivamente, ayudaría a China a cruzar una 
línea roja de la geopolítica mundial: convertirse en el polo de poder de mayor influencia en Asia Pacífico, la región más dinámica del mundo, que posee más de $40 \%$ del PIB mundial y constituye actualmente el tablero principal en donde se dibuja el mapa del poder mundial.

\section{Reflexiones finales}

El cambio de gobierno de Estados Unidos, a partir de lo cual se debilitaron las fuerzas globalistas, le permitió a China avanzar en términos estratégicos e incluso incorporar a Japón en el BRI, lanzar la RCEP y profundizar su expansión en Eurasia, continente clave en la geopolítica mundial. También continuó su avance en África y en América Latina. Este nuevo momento político mundial se vio reflejado en la cumbre del Foro de la Franja y de la Ruta realizado en mayo de 2017 al que asistieron más de 1200 delegados de 130 países y 29 jefes de Estado, junto con 70 organizaciones internacionales. También es una muestra del avance de China la posición de Xi Jinping en Davos en donde defendió la liberalización del comercio y la inversión, en contra del proteccionismo estadounidense.

Como sucedió históricamente con las grandes potencias industriales, una vez que alcanzan cierto nivel de desarrollo relativo y competitividad, convirtiéndose en nuevos centros de la economía global, cambian las posiciones proteccionistas por posiciones más cercanas al libre mercado. Además, esta primacía en la dimensión productiva, que se corresponde con una reducción acelerada de la brecha tecnológica (donde incluso lidera algunas ramas), también está acompañada por los otros dos planos centrales del dominio económico mundial en los cuales el gigante asiático comenzó a tallar: la ruptura de los monopolios comerciales y financieros del Norte Global, en cuyo vértice se encuentra Estados Unidos.

También hay riesgos y no se trata, necesariamente, de un camino lineal hacia el ascenso. En este sentido, entre los más inmediatos, se hallan los efectos negativos en la economía china que pueda tener llamada "guerra comercial", la agresividad de Washington para impedir el avance tecnológico de China y el desarrollo de un conjunto de tensiones geoestratégicas a su alrededor. Además, Beijing necesita asegurar el aprovisionamiento de materias primas y energía que el actual gobierno de Estados Unidos está dispuesto a limitar utilizando la primacía naval -aunque dicha primacía ya esté en crisis en el Pacífico occidental según informes de Estados Unidos. (RT, 2020). 
A diferencia de Estados Unidos, China está rodeada de potencias que miran con recelo su ascenso y Washington busca hacer confrontar. A ello se le agrega un conjunto de conflictos territoriales clave en el Mar de China. Es bueno recordar que una cuestión fundamental en la Segunda Guerra Mundial fue el bloqueo petrolero de Estados Unidos a Japón en el Pacífico, que impulsó al Imperio del Sol Naciente a atacar Pearl Harbour. Por ello, entre otras cuestiones y con las contradicciones señaladas, Estados Unidos busca controlar Medio Oriente, bloquear la inversión de China en América Latina o establecer una sólida presencia político militar a través del USINDOPACOM.

También es cierto que para Estados Unidos y aliados el riesgo de apostar a cualquiera de estas alternativas de escalada es enorme. Debería para ello "desconectar" ambas economías, algo bastante improbable, por lo menos en el mediano plazo, aunque funcionarios de la actual administración estadounidense lo tengan como objetivo. Tampoco resulta fácil establecer los "cálculos" que dominarán las próximas decisiones.

También se enfrenta China a otro escenario: un triunfo de las fuerzas globalistas en Estados Unidos, que recupere el TPP (junto con el TTIP), refuerce las alianzas del polo de poder angloamericano en Asia Pacífico e Índico para generar un equilibrio de poder favorable, debilite a Rusia y el desarrollo del emergente eje Eurasiático y logre establecer las "reglas de juego" del siglo XXI, probablemente bajo un capitalismo en crisis, pero voraz. Esta estrategia no implica la "destrucción" de China, sino su absorción como territorio de solución espacio-temporal de la crisis de sobre-acumulación del Norte Global. Sin embargo, ello también enfrenta otro dilema: la crisis del sistema mundo moderno como tal y, en este sentido, la imposibilidad de una sucesión como las anteriores. Aunque, es probable, que China quede subsumida en una solución más polarizada, antidemocrática y opresiva del orden mundial, en manos de una oligarquía financiera.

Por otro lado, existen desafíos más profundos para el ascenso chino y de Asia-Pacífico. Podemos señalar dos de los más importantes, estrechamente relacionados: la imposibilidad de incorporar a una sexta parte de la población mundial al centro del sistema, por el patrón estructural de desarrollo desigual y combinado inherente al moderno sistema mundial (que además está en proceso de desmoronamiento). Y al mismo tiempo, la imposibilidad de realizar dicha incorporación en los 
actuales parámetros de consumo y explotación de la naturaleza, sin avanzar hacia el abismo ambiental.

La reconfiguración imperial de Estados Unidos y las fracturas "internas" frente al ascenso de China son cuestiones inherentes al cambio de época que atraviesa la humanidad. Es probable que, si el declive se agudiza, las polarizaciones sean aún más fuertes. Cada fuerza intenta enfrentar el declive de los Estados Unidos dentro de sus perspectivas estratégicas, moldeadas en relación a sus intereses. En el gobierno de Trump observamos la apuesta estratégica a un nacionalismo económico neohamiltoniano a lo Pinkerton y Navarro combinado, como vimos anteriormente, con lineamientos propios del neoconservadurismo, que apuestan al control del Medio Oriente, el unilateralismo y la supremacía militar absoluta -encarnado en la figura del dimitido John Bolton, el jefe de gabinete Mike Pompeo y el vicepresidente Mike Pence. También aparecen intentos de reforzar las alianzas militares en la zona Indo-Pacífico (India, Taiwán) e intervenir en los principales conflictos geoestratégicos de la región. Por otro lado, ha quedado desplazada la visión neorrealista de contención, multilateralismo y equilibrio de poder, más cercana a los globalistas, como también las concepciones liberales (aunque también con su versión neorrealista) de establecer las "reglas de juego" del siglo XXI. Predomina la idea en Washington de romper las reglas de juego.

Paradójicamente, la actual conducción de los Estados Unidos puede ser la más favorable para el ascenso de China - de hecho, prácticamente le está acercando aliados euroasiáticos claves como Rusia, Irán, Turquía y Alemania- pero a la vez la más "peligrosa". No se sabe hasta dónde puede llegar la escalada de la guerra, no sólo en el plano comercial-como parte de una Guerra Mundial híbrida-, sino también en el militar.

\section{Bibliografía}

ALCONADA MON, Hugo "Preocupa a EE.UU. la influencia de China en América latina. En especial en la Argentina y Brasil". La Nación. Buenos Aires, 7 abril 2005.

AMIN, Samir. El capitalismo en la era de la globalización. Buenos Aires: Paidós, 1998

AMIN, Samir, “China 2013". Monthly Review. vol. 64, №10, marzo 2013.

ARRIGHI, Giovanni. Adam Smith en Pekín. Orígenes y fundamentos del siglo XXI. Akal, Madrid, 2007 
ARRIGHI, Giovanni; SILVER, Beverly. Caos y Orden en el Sistema-Mundo Moderno. Madrid: Akal, 2001.

BANCO MUNDIAL. Exportaciones de bienes y servicios por país. Datos macro Banco Mundial. 2020.

BORÓN, Atilio. América Latina en la geopolítica del Imperialismo. Buenos Aires: Ediciones Luxemburg, 2014.

BRZEZINSKI, Zbigniew. El gran tablero mundial. La supremacía estadounidense y sus imperativos geoestratégicos. Buenos Aires: Paidós, 1998.

CASTORENA SÁNCHEZ, Casandra; GANDÁSEGUI, Marco y MORGENFELD, Leandro. Estados Unidos contra el mundo: Trump y la nueva geopolítica. Buenos Aires: CLACSO/Siglo XXI, 2018.

CLINTON, Hillary. "America's Pacific Century”. Foreign Policy, octubre 2011.

CONGRESSIONAL RESEARCH SERVICE. "China Naval Modernization: Implications for U.S. Navy Capabilities". Background and Issues for Congress. Marzo 2020.

EFE, "Trump ordena investigar si las importaciones de acero amenazan la seguridad nacional". Agencia EFE. 20 abril 2017. Disponible en: https://www.efe.com/efe/america/economia/trump-ordena-investigar-si-lasimportaciones-de-acero-amenazan-la-seguridad-nacional/20000011-324313 7. Accesado en 30.08.2020

FINANCIAL TIMES, "Europe and US in race to keep TTIP on track". Financial Times. 21 de septiembre de 2016.

GARCÍA LINERA, Álvaro. El Estado en transición. Bloque de poder y punto de bifurcación. En: La potencia plebeya. Buenos Aires: Prometeo Libros, 2008

HARVEY, David. EI Nuevo Imperialismo. Madrid: Akal, 2004.

HUNTINGTON, Samuel. The Clash of Civilizations and the Remaking of the World Order, New York: Simon \& Schuster, 1996.

MACKINDER, Halford. "El pivote geográfico de la historia". Geopolítica(s) vol 1, n², pp. 301-319, 2010.

MARTINS, Carlos Eduardo. Globalização, dependência e neoliberalismo na América Latina, Boitempo: São Paulo, 2011.

MERINO, Gabriel E. "Lucha entre polos de poder por la configuración del orden mundial. El escenario actual". Revista de Estudios Estratégicos $\mathrm{N}^{\circ} 1$, 
Centro de Investigaciones en Política Internacional (CIPI), Instituto Superior de Relaciones Internacionales (ISRI), La Habana, 2014, pp. 13-35.

MERINO, Gabriel E., El Grupo Productivo y el cambio de "modelo". Luchas por la conducción del estado en Argentina entre 1999 y 2003. Buenos Aires: Editorial Universitaria UNAM, CEFIPES, CEPES, 2015.

MERINO, Gabriel E. "Tensiones mundiales, multipolaridad relativa y bloques de poder en una nueva fase de la crisis del orden mundial. Perspectivas de América Latina". Geopolítica(s): Revista de estudios sobre espacio y poder, vol. 2, núm. 7, Universidad Complutense de Madrid, Madrid, 2016.

MERINO, Gabriel E., "Los tratados comerciales y las luchas globales en la era Trump". Realidad Económica, N 313, IADE, Buenos Aires, pp. 9 a 40, 2018 a.

MERINO, Gabriel E., Trump: la fractura en Estados Unidos y sus implicancias en la transición histórica actual En: Casandra Castorena Sánchez, Marco A. Gandásegui, Leandro Ariel Morgenfeld (Eds.), Estados Unidos contra el mundo: Trump y la nueva geopolítica, Buenos Aires: CLACSO/Siglo XXI, 2018b.

MERINO, Gabriel E. "Guerra Comercial y América Latina". Revista de Relaciones Internacionales, $N^{\circ} 134$, Centro de Relaciones Internacionales de la UNAM, México, pp. 67-98, 2019

MERINO, Gabriel E. y TRIVI, Nicolás. La Nueva Ruta de la Seda y la disputa por el poder mundial. En Bogado, L, Caubet, M y Staiano, F. (Eds.) China: una nueva estrategia geopolítica y global. La iniciativa de la franja y la ruta. La Plata: Instituto de Relaciones Internacionales y Centro de Estudios Chinos de la UNLP, 2019.

NING Su; CHUANKAI, Yang. "Silk Road Cities': Characteristics and development significance of urban pivots along the 'Belt and Road' ". The Belt \& Road Studies, vol. 2, Shanghai Academy of Social Science, autumn 2018.

PARRA PÉREZ, Águeda. "OBOR: las 5 claves de la mayor iniciativa de infraestructuras mundial liderada por China". Documentos de Opinión, Instituto Español de Estudios Estratégicos, 2017.

POMERANZ, Kennet. The Great Divergence: China, Europe, and the Making of the Modern World Economy. United Kingdom: Princeton University Press, 2000.

RT (RUSSIA TODAY), "Se prepara China para una guerra con Japón y Occidente", Russia Today. 29 de septiembre de 2014.

RT (RUSSIA TODAY). "El Congreso de EE.UU. advierte que China podría superar el potencial de la Armada estadounidense", Russia Today. 2 de junio de 2020 
SPUTNIK. "Consejero de Seguridad de la Casa Blanca reafirma la vigencia de la Doctrina Monroe", Sputnik. 18 de abril de 2019.

STAVRIDIS, James. "Vladimir Putin hates the TTIP". Foreign Policy, 19 de noviembre de 2014.

SUÁREZ SALAZAR Luis. Estados Unidos vs Nuestra América: el gobierno de Barack Obama (2009-2017). La Habana: Editorial de Ciencias Sociales, 2017.

TAVARES, Maria da Conceição; FIORI, José Luís. Poder e dinheiro. Uma economia política da globalização. Rio de Janeiro: Vozes, 2017.

WALLERSTEIN, Immanuel. La decadencia del poder estadounidense. Buenos Aires: Le Monde Diplomatique/ Capital Intelectual, 2006.

ZHU, X. "Understanding China's Growth: Past, Present, and Future". Journal of Economic Perspectives, vol. 26, N4, 103-124, 2012. 